\title{
Lived Experiences of COVID-19 Survivors in Nepal: A Phenomenological Analysis
}

\author{
Suvekshya Silwal,' Deepika Khadgi, ${ }^{1}$ Anju Kumari Mahato,' Saraswati Basnet, ${ }^{1}$ Sheela Thapa, ${ }^{2}$ Achala \\ Niraula, ${ }^{1}$ \\ 'Department of Adult Health Nursing, TU IOM Biratnagar Nursing Campus, Nepal ${ }^{2}$ School of Nursing \& Midwifery Karnali \\ Academy of Health Sciences, Jumla
}

\section{ABSTRACT \\ Introduction}

Novel coronavirus (COVID-19) is the new public health crisis rapidly threatening the world. A deeper understanding of these devastating lifetime experiences helps to develop a more complete picture of how holistic health may have been affected in survivors from pandemic. The objective of the study was to explore the lived experiences of COVID-19 survivors.

\section{Methods}

A phenomenological qualitative research design was adopted following purposive sampling traced from the hospital record of Koshi Covid Hospital of Biratnagar, Province 1 Nepal. Based on principles of data saturation, ten covid survivors were interviewed following the interview guide. The obtained data were transcribed in reference to notes and tape recordings, and themes were generated. The data collection and analysis were carried out simultaneously, using thematic analysis phases of Gibson manually.

\section{Results}

The study findings emerged five themes: key stakeholders in COVID-19 pandemic, mystery of COVID-19, social stigma and discrimination, mass media influence, and safety measures. Most (8/10) of the participants reported COVID-19 as mysterious disease with unknown cause and few (2/10) reported peculiar symptoms (something stuck in throat, presence of abscess in chest, etc). Seven of them faced stigmatizing responses from health care workers and most of them reported inadequate health counseling at health care institutions.

\section{Conclusions}

COVID-19 survivors were scared of infecting their family and neighbors and of death related to infection. Interventions for breaking the chain of transmission were carried out, however, healthcare workers' approach of care was inadequate along with stigma and discrimination. Adequate counseling is vital to address physical and psychological issues among survivors.

Keywords: COVID-19 Survivors; Lived experiences; Phenomenology; Qualitative Study

Correspondence: Suvekshya Silwal, Department of Adult Health Nursing, TU IOM Biratnagar Nursing Campus, Nepal. E-mail: ssuvusilwal@gmail.com. Phone: +977-9842354348. 


\section{INTRODUCTION}

Globally each year disaster events of pandemic, epidemic, earthquake, floods, drought, tsunamis are increasing killing thousands of people ${ }^{1}$ and at present, a new public health crisis 2019 novel coronavirus is threatening the world with its sudden emergence and rapid spread. Since 5th May 2021, total cases in Nepal is 359,610 with recovered cases $289,783^{2}$. As of $8^{\text {th }}$ May, there are total 36645 COVID-19 cases in Province 1, $\mathrm{Nepal}^{3}$.

Patients with confirmed or suspected 2019$\mathrm{nCoV}$ may experience fear of the consequences of infection, and those in quarantine might experience boredom, loneliness, and anger ${ }^{4}$. Though the Nepal government has developed policy focusing on prevention of stigma and discriminations associated with COVID-19, Nepal's second case of Covid-19, received hate mail and death threats on social media once her case was made public ${ }^{5}$.

The main objective of the study is to explore COVID -19 survivors' experiences and secondary objectives to identify major concerns faced by them regarding the response of family, friends and society, health care workers and their knowledge on preventive measures and coping strategies to normal life after recovery.

\section{METHODS}

Qualitative phenomenological research design was used to explore the lived experiences of COVID-19 survivors. Phenomenological approaches are based on a paradigm of personal knowledge and subjectivity, and emphasize the importance of personal perspective and interpretation. The setting of the study was survivors' own home, a natural setting as it provides opportunity to observe the real situation where they live and familiarity may help the participants to comfortably result in more productive information.

The population of the study was those COVID-19 patients who have been recovered and discharged from COVID-19 Koshi Hospital, Biratnagar, Province 1. The COVID-19 Koshi Hospital was established on 15th Chaitra 2076 B.S. in Salt Trading Building, Biratnagar-10 with the aim to provide curative services to those diagnosed with Covid-19. Patients are treated in this hospital from different districts, where the majority of the cases were from Sunsari, Jhapa, Udayapur, Morang. (Source: Hospital record of COVID-19 Koshi Unit, 29th June, 2021).

Sample size was determined on the basis of informational needs following the guiding principle of data saturation. With a fairly homogenous sample, fewer than ten cases may suffice $^{6}$. Based on principles of data saturation, ten COVID-19 survivors with at least one month of recovery period were traced from the hospital inventory. Purposive sampling method was used for the selection of the samples considering the inclusiveness of age above 20 years, sex and place of residence. Face-to-face interview was taken with a semi-structured interview guide. An interview is a joint product of what interviewees and interviewers talk about together and how they talk with each other. The records of an interview that the researchers made were used for analysis and interpretation to get a picture of the study phenomenon ${ }^{7}$. The interview guide consisted of two parts, sociodemographic characteristics of participants and in-depth interview guide of participants. Credibility was enhanced with the opinion of the subject matter experts and peer feedback. The verbatim collected from the participants were transcribed by listening to the audio recording and observations during face-face interviews to ensure the closeness of the data which helped to maintain dependability. To enhance the quality of research findings, trustworthiness of data 
was maintained with repeated contacts (when needed) with the related participants. Intercoder reliability was maintained by development of codes and themes with coordination in other department faculties.

Ethical clearance was obtained from the Institutional Review Committee (IRC) of TU IoM [Ref. no. 28/(6-11)E²/077/078]. Formal permissions to access information of COVID 19 patients were obtained from the Ministry of Social Development, Province 1 and Head of Department of COVID-19 Unit, Koshi Hospital. Written informed consent for data collection via interview and audio recording was obtained from each participant before the interview. Confidentiality of the collected information was ensured by coding the interview records of participants. Precaution was taken in every step of the study to safeguard the right and welfare of the participants.

The data was collected using an in-depth interview guide for about 60-90 minutes for each participant. However, their interest to continue/ discontinue was taken into consideration. The duration of the data collection with simultaneous analysis was about three months from December 15th 2020 till March 15th 2021. Responses corresponding to the concerned matter were followed by probing questions. Until the data saturated, further repeated interviews were carried out with participants for the assurance of clear information. Before carrying out the data collection procedure, orientation on interview technique was carried out among all the investigators for maintaining homogeneity. All investigators were involved in the first interview following informed consent by the participant. Analysis of data was achieved with the thematic analysis developed by Gibson 2006 (as cited in $^{8}$ ) which consisted of six phases.

\section{RESULTS}

The findings of the study were obtained from analysis of the narrative description of the participants where table 1 reveals that most participants belonged to the age group of 20-30 years of age with male: $70 \%$ male and female: $30 \%$. Forty percentage of male participants had completed their higher secondary whereas $20 \%$ female had completed their higher secondary level of education.

\begin{tabular}{|c|c|c|}
\hline $\begin{array}{c}\text { Socio-Demographic } \\
\text { Characteristics }\end{array}$ & Male & Female \\
\hline \multicolumn{3}{|l|}{ Age } \\
\hline $20-30$ years & 3 & \multirow{4}{*}{3} \\
\hline $31-40$ years & 1 & \\
\hline $41-50$ years & 1 & \\
\hline 51 years and above & 2 & \\
\hline \multicolumn{3}{|l|}{ Education } \\
\hline Literate & 1 & \\
\hline Lower secondary & 1 & \\
\hline Secondary & 1 & 1 \\
\hline Higher secondary & 4 & 2 \\
\hline \multicolumn{3}{|l|}{ Marital status } \\
\hline Unmarried & 2 & 1 \\
\hline Married & 5 & 2 \\
\hline \multicolumn{3}{|l|}{ Occupation } \\
\hline Security/Watchman & 1 & \\
\hline Health worker & 2 & \\
\hline Ward cleaner & 1 & \\
\hline Priest & 1 & 3 \\
\hline Policeman & 1 & \\
\hline Retired & 1 & \\
\hline
\end{tabular}

Table 2 reveals the thematic analysis of themes from the narrative statements of the participants coded from the transcripts. Twenty six codes were generated from the narrative statements. 
Based on self-reported experiences, efforts were made to get collective meaning from those codes where they were merged based on their semantic meaning in order to form categories. Altogether 10 sub-themes/ categories such as: frontline workers, Basic Knowledge on transmission of COVID, Nature of disease, Post covid experience, Negligence, Care and support, Value system, Information circulation of social media, Plans and policies and Prevention and Practice were formed. Out of those identified categories, further analysis was done by combining related sub-themes to form the coherent patterns and themes generated after grouping the cluster of sub-themes/categories with their conceptual meanings respectively.

\begin{tabular}{|c|c|c|c|}
\hline S.N. & Codes & Sub-themes/Categories & Themes \\
\hline 1. & During patient care & \multirow{4}{*}{ frontline workers } & \multirow{4}{*}{$\begin{array}{l}\text { Key stakeholders in COVID } \\
\text { pandemic }\end{array}$} \\
\hline 2. & Workplace infection & & \\
\hline 3. & Dedication to job & & \\
\hline 4. & Workload and Responsibilities & & \\
\hline 5. & Dilemma in symptoms of COVID & \multirow{2}{*}{$\begin{array}{l}\text { Basic Knowledge on } \\
\text { transmission of COVID }\end{array}$} & \multirow{6}{*}{ Mystery of COVID-19 } \\
\hline 6. & Unaware about transmission of disease & & \\
\hline 7. & Physiological responses & \multirow{3}{*}{$\begin{array}{l}\text { Nature of disease } \\
\text { Post covid experience }\end{array}$} & \\
\hline 8. & Yelling of patients & & \\
\hline 9. & Feeling of lethargy & & \\
\hline 10. & Physical and emotional response & & \\
\hline 11. & Infected relatives during visits & \multirow{2}{*}{ Negligence } & \multirow{10}{*}{$\begin{array}{l}\text { Social Stigma } \\
\text { discrimination }\end{array}$} \\
\hline 12. & Social contact & & \\
\hline 13. & Fear of infecting near and dear ones & \multirow{4}{*}{ care and support } & \\
\hline 14. & Feeling of guilt & & \\
\hline 15. & Worrying about life & & \\
\hline 16. & Family Response (crying, Supportive, ) & & \\
\hline 17. & Discrimination in workplace & \multirow{4}{*}{ Value system } & \\
\hline 18. & Rudeness of health workers & & \\
\hline 19. & Opinion towards health care & & \\
\hline 20. & Lack of communication & & \\
\hline 21. & $\begin{array}{l}\text { False information about COVID-19 news, } \\
\text { social apps facebook, etc }\end{array}$ & \multirow{2}{*}{$\begin{array}{l}\text { Information circulation of } \\
\text { social media }\end{array}$} & \multirow{3}{*}{ Mass media influence } \\
\hline 22. & Lack of awareness about disease & & \\
\hline 23. & Suggestions to plan makers & Plans and policies & \\
\hline 24. & Safety measures & \multirow{3}{*}{ Prevention and practice } & \multirow{3}{*}{ Safety measures } \\
\hline 25. & Lifestyle practices & & \\
\hline 26. & Dietary and eating pattern & & \\
\hline
\end{tabular}


Finally, five themes emerged from the lived experiences of COVID-19 survivors as listed below:

\section{Theme 1: Key stakeholders in COVID-19 pandemic}

Five out of ten (5/10) participants reported that they had acquired the infection from their workplace. They were involved in hospital settings: one as an SBA trainee, three of them worked in OPD, one as security guard.

The narrative statements reflecting the respondents' expression regarding the cause of infection of COVID-19 stated:

"I got infected with COVID during SBA training posting". (Code 101)

"It was the 3rd PCR test which I got positive and I have no idea how I got infections. I used to stay at the gate. I had to talk at first and contact many visitors". (Code 103)

While three out of ten $(3 / 10)$ reported that they got infected from social contact like contact with friends, relatives in the religious program and $1 / 10$ reported unknown about the cause of infection.

"I had a ritual program in my house and there was gathering and from there I might have got the infection".(Code 110).

"I was active and used to participate in almost every socio-cultural event of family and society even during Corona. One day, I had gone to my nephew's home in the death ritual of a family member and when I came back home, I started feeling uneasy, I then informed the ward members and next morning a sample of mine and my wife was taken for Corona test". (Code 105)

\section{Theme 2: Mystery of COVID-19}

Eight (8/10) of the participants reported the infection as mysterious regarding the cause, transmission and severity of COVID-19 infection. Almost all of them reported that the major symptoms were fever, headache, bodyache, chest pain, sore throat and feeling of weakness however symptoms vary from individual to individual.

"COVID is normal but the symptoms different from individual to individual. I think it's quite different from other diseases, I had a different type of throat pain, slight headache, slight backache, it's quite different. How one gets symptoms varies, something present deeply in my neck........... I got to know that my PCR result was positive, ... as most of the people were getting infected, I didn't have such fear, even though I was worried about what would happen to me ... ?? I didn't have any such type of issues but also I was somewhat worried about what would happen?". (Code 103)

"After 3-4 days, symptoms became worse and started to have stridor, severe nausea-vomiting (immediately after meals or even while eating), burning sensation at the back (like sitting in flame). Now I was afraid and thought it is better to go to the hospital for treatment. I informed the concerned person and moved to Covid hospital'. (Code 105)

"Because during my job period here at hospital, I have seen many healthy patients of corona positive who came by walking themselves, used to die within 3-4 days of hospitalization. Initially, those patients were healthy and normal looking but after admission, their condition used to worsen and became serious and finally went out of the hospital as dead bodies". (Code 102)

\section{Theme 3: Social Stigma and Discrimination}

Seven out of ten $(7 / 10)$ of the participants reported responded feeling of stigmatising responses and discrimination from health care workers during hospital stay.

"When my test for Corona came positive, my employers, colleagues and seniors told me not to come to duty for fear of transmission and they started 
to maintain a huge physical distance with me. They told me not to come close to them and said to get admitted to the Corona Ward. Nobody addressed my request to let me stay in a corner of the quarantine and I was forcefully shifted to the Recovery ward of Covid hospital". (Code 102)

"When I first came to the hospital, I didn't feel good because the people were quite rude and instead of a 2 meters gap, the hospital staff stood 10 meters away from me and all the infected patients. I felt like an alien". (Code 106).

Two of them reported that the isolation was utmost as it was for protection for ownself and friends and family and they reported that health care workers must isolate them in order to protect themselves from the transmission and society too supported them to fight against the virus and six (6/10) of them were satisfied with the health care facilities provided by the hospital.

"My family members told me to stay at home but I chose to go Covid hospital as in my residence there was only one toilet and it was difficult to maintain cross contamination .....society was very supportive to me. They didn't boycott me at the crisis time and took good care of mine". (Code 106)

"I felt relieved and was optimistic about my health when I was at Covid hospital. All the facilities seemed satisfactory like service, food, communication, behavior of health persons, environment". (Code 105)

"Behavior of Doctors nurses and all staff was good. The doctors and nurses team visited once a day and counseled for adequate diet, steam inhalation, warm fluid intake and respiratory exercises". (Code 104)

\section{Theme 4: Mass media Influence}

Few (2/10) reported that false information circulation of social media and repeated news on such issues of infection and death plays an important role in creating anxiety and fear among people.

"Main is the news which makes the condition worse by highlighting the number of infectious cases, number of deaths, which creates fear in the general public and makes people hopeless. Person being alone is hopeless initially as no relatives or near ones are allowed to remain with and further makes the person more hopeless". (Code 108).

"The news highlighting death cases and some humors of dying after COVID and news displaying dead bodies wrapped with plastic wrappers create more fear.....".(Code 101).

\section{Theme 5: Safety Measures}

Almost all participants reported safety measures as: proper handwashing, wearing mask and avoiding crowds were the best ways to prevent from getting the infections

"I still use safety measures like masks, Hand washing in friend circles and patient care". (Code 101)

"For prevention we need to maintain distance, wash hands, wear masks and be less exposed in crowded areas". (Code 107)

"Frequently hand washing, wearing masks, preventing crowded areas, and maintaining distance were very effective". (Code 110)

\section{DISCUSSION}

The findings presented as different themes, sub-themes and codes are discussed in the light of existing literature with five major themes: 1. Key stakeholders in COVID-19 pandemic; 2. Mystery of COVID-19; 3. Social Stigma and Discrimination; 4. Mass Media influence and 5. Safety Measures.

\section{Key Stakeholders in COVID-19 Pandemic:} During the sharing of experiences, participants who were health care providers shared their feeling of calling for the profession and their role as front liners 
during the pandemic because of which they could not give up from their responsibility rather they worked for the patient and got infected themselves. Similar findings were revealed from the study ${ }^{9-10}$.

Out of ten, five participants reported their involvement in hospital settings due to their nature of job and acquired COVID-19 infection from their workplace and this finding is similar to the qualitative study conducted $^{9}$ among active workers (nurses) caring for Covid patients which reported that all of the contracted infection from the infected patients they were caring for. Yet another study revealed the psychological trauma of contracting infection among nurses while working in the corona unit as many of their co-workers were infected ${ }^{10}$.

2. Mystery of COVID-19: COVID-19 is a new health problem and emerging as a deadly viral infection with no exact treatment. Every other day new facets of virus and disease were revealed. Many research and studies on Covid and its treatment were conducted throughout the world without any concluding results. Amidst this situation, everyone including the healthcare workers had anxiety due to the nature of disease $^{11}$ and similar experiences were shared by most of the study participants. They expressed interweaving assumptions on how they got infected despite wearing masks as well as about the nature of the disease. Two of the ten participants showed their repeated query and curiosity about the sudden death of the healthy-looking COVID-19 patients after their admission in the COVID Unit. One of the respondents shared the hearing of mysterious yelling of the patients a few hours before the death of those patients. Similar kinds of experiences about disease progression and recovery, changes in behavior were shared in other literature ${ }^{12}$ as well.

3. Social Stigma and discrimination: Present study result found that stigma and discrimination faced by the covid-19 survivors in their workplace, in the health care institutions and society which is supported by the study conducted in Wuhan which shows that stigmatising responses faced by covid-19 patients of staying away from their families, discrimination, prejudice, suspension and dismissal from work ${ }^{13}$. Study conducted on a phenomenological ucted on SARSCoV-2 infection and Covid-19: the lived experience and perceptions of patients in isolation and care in an Australian country healthcare setting supports the study findings which reports that covid-19 patients conveyed both positive and negative lived experiences of infection, isolation, and illness by society ${ }^{14}$.

4. Mass Media Influence: Present study result found that role of media and health policy create the anxiety of COVID survivor whereas the study conducted among 14 Covid-19 survivors in Northern Iran result shows that doubts about accuracy of information provided by media being disorderly with information and exacerbated anxiety by hearing conflicting news led to confusion among Covid patients ${ }^{15}$. Similarly the other study is similar to the study findings which reported that social media platforms were another factor of significance is the explosion of information" creating a "pandemic of panic." In a recent study looking at the awareness of the general public on COVID-19 done across the USA and UK, a number of misconceptions regarding this viral infection and the increasing ability 
of social media to influence beliefs were identified $^{17}$.

The study findings yields that due to the misleading information of COVID-19 by social media and repeated highlighting the number of deaths than recovery creates anxiety and fear on healthy as well as unhealthy or diseased one which is supported by the study conducted ${ }^{18}$ which reported that with the significant influence and omnipresence of social media, public health officials and scientists compete with other sources of information that may contain potentially misleading information on this pandemic creating anxiety in public as the internet and online platforms are easily accessible source containing healthcare information thus, it is important to evaluate the validity and quality of accurate medical information delivered to the general public.

5. Safety measures: The study findings suggest that handwashing, wearing mask and maintaining distance are the utmost safety measures for prevention from the contact of the infection which is supported by the similar study in health care settings which require frequent and close contact between healthcare practitioners and patients, infection prevention and control (IPC) measures such as the use of personal protective equipment (PPE), hand hygiene, and frequent cleaning and sanitization are essential to mitigate the spread of infectious disease $^{19-20}$.

Similarly the other study also supports the study findings which reports that the concept of social distancing, in which individuals have to maintain at least one meter distance from each other, is being widely publicized by the WHO, CDC, and ICMR for preventing spread of the virus. Respondents with over $40 \%$ stating they would rely on sources like social media such as WhatsApp and Facebook for advice about safety measures ${ }^{21}$.

\section{CONCLUSIONS}

The study findings emerged five themes: key stakeholders in COVID-19 pandemic, mystery of COVID-19, social stigma and discrimination, mass media influence, and safety measures. The infection was found to be mysterious with unknown cause and peculiar physical symptoms varying from individual. Stigmatizing responses snd discrimination was found in workplace and in hospital with lack of appropriate and proper health counseling and support from health care providers. Though all were motivated to seek health care services due to fear of infecting their family and neighbors; they were scared of death related to COVID-19, being isolated and alone.

\section{ACKNOWLEDGEMENTS}

We are indebted to the entire faculties and staffs of TU IoM Biratnagar Nursing Campus and research advisors Professor Dr. Sarala Joshi, Former Assistant Dean, TU IoM Maharajgunj; Professor Dr Ramsaran Mehata, BPKIHS, Dharan; Professor Dr Madhu Sudan Subedi, Patan Academy of Health Sciences and Associate Professor Dr. Mandira Lamichhane, Research Fellow at Policy Research Institute, a think tank of Government of Nepal for their continuous guidance and support during this study. At last but not least thanks to Nepal Health Research Council (NHRC), Nepal for selecting this research study for oral presentation in $7^{\text {th }}$ National summit of Health and Population scientist in Nepal.

Conflict of Interest: None 


\section{REFERENCES}

1. Koirala J, Acharya S, Neupane M, Phuyal M, Rijal N, Khanal U.P. Government Preparedness and Response for 2020 Pandemic Disaster in Nepal: A Case Study of COVID-19. [Internet]. 2020. [cited 2020 March 30]. Available from file://C:/Users/User/Desktop/UGC/ literatures\%20on\%20Covid-19/SSRNid3564214.pdf

2. Worldometer. COVID-19 CoronaVirus Pandemic [Internet]. 2020. Available from: https://www.worldometers.info/ coronavirus/\#news

3. Ministry of SocialDevelopment. Province 1. COVID-19 Report. 2021 May 8. [cited 2021 May 8]. Available from http://mosd. p1.gov.np/sites/mosd/files/2021-05/ COVID\%20Report\%202078-01-24\%20 \%20\%20\%20Province\%201.pdf

4. Xiang $\mathrm{Y} \mathrm{T}$, Yang $\mathrm{Y}, \mathrm{Li} \mathrm{W}$, Zhang $\mathrm{L}$, Zhang Q, Cheung T, Ng C H. Timely mental health care for the 2019 novel coronavirus outbreak is urgently needed. The Lancet Psychiatry. [Internet]. 2020 Mar 1. [cited 2020 May 8]; 7(3):228229. Available from https://www. thelancet.com/journals/lanpsy/article/ PIIS2215-0366\%2820\%2930046-8/fulltext doi:10.1016/ S2215-0366(20)30046-8

5. Poudel A. Stigma against health workers, patients and area locals continues in Covid19 hotspots [Internet]. 2020. [Cited on May, 29]. Available from https:/KathmanduPost.com/ national/2020/05/01/stigma-againsthealth-workers-patients-and-arealocals-continues-in-covid-19-hotspots). https://tkpo.st/2WikUh5
6. Polit DF, Beck CT. Nursing Research. 9th ed. New Delhi, India: Wolters Kluwer (India) Pvt. Ltd.; 2011

7. Joshi S. Qualitative research approaches for health personnel. (2008). Kathmandu: Makalu.

8. Javadi M, Zarea K. Understanding Thematic Analysis and its Pitfall. J Client Care [Internet]. 2016;1(1). Available from: http://journals.lexispublisher.com/jcc/ paper/20011

9. He J, Liu L, Chen X, Qi B, Liu Y, Zhang $Y$. The experiences of nurses infected with CO ID 19 in Wuhan, China: A qualitative study. Journal of Nursing Management.[Internet]. 2021 Jan. https:// doi.org/10.1111/jonm.13256

10. Fawaz M, Samaha A. The psychosocial effects of being quarantined following exposure to COVID-19: A qualitative study of Lebanese health care workers. International Journal of Social Psychiatry. [Internet. 2020 June (cited on 2021 April); 66(6):560-65. https://doi. org/10.1177/0020764020932202

11. Galehdar N, Kamran A, Toulabi T, Heydari H. (2020). Exploring nurses' experiences of psychological distress during care of patients with COVID-19: a qualitative study. BMC Psychiatry. [Internet]. 2020 Oct 6 (cited on 2021 April); 20(489). Assessed from https:// bmcpsychiatry.biomedcentral.com/ articles/10.1186/s12888-020-02898-1

12. Sun $N$, Wei L, Wang $H$, Wang $X$, Gao $\mathrm{M}, \mathrm{Hu}$ X, et al. Qualitative study of the psychological experience of COVID-19 patients during hospitalization. J Affect Disord [Internet]. 2021;278(24):15-22. Available from: https://doi.org/10.1016/j. 
jad.2020.08.040

13. Morioka S, Saito S, Hayakawa K, Takasaki J, Suzuki T, Ide S, et al. Psychiatric burdens or stress during hospitalization and concerns after discharge in patients with severe acute respiratory syndrome coronavirus-2 isolated in a tertiary care hospital. Psychiatry Res. 2020;289(January):19-21.

14. Shaban RZ, Nahidi S, Sotomayor-castillo C, Li C, Hackett K, Bag S. SARS-CoV-2 infection and COVID-19: The lived experience and perceptions of patients in isolation and care in an Australian healthcare setting Ramon. 2020;(January). Available from: https://www.ncbi.nlm.nih. gov/pmc/articles/PMC7466942/

15. Moradi Y, Mollazadeh F, Karimi P, Hossein Gholipour K, Baghaei R. Psychological disturbances of survivors throughout COVID-19 crisis: a qualitative study. BMC Psychiatry. 2020;20(1):1-8.

16. Depoux A, Martin S, Karafillakis E, et al. The pandemic of social media panic travels faster than the COVID-19 outbreak. J Travel Med.2020;27(3):taaa031.

17. Geldsetzer P. Knowledge and Perceptions of COVID-19 Among the General Public in the United States and the United Kingdom: A Cross-sectional Online Survey. Ann Intern Med [Internet]. 2019;171(6):441-3. Available from: https://www.ncbi.nlm.nih.
gov/pmc/articles/PMC7086377/pdf/aimolf-M200912.pdf

18. Vance, K., Howe, W., \& Dellavalle, R. P. (2009). Social internet sites as a source of public health information. Dermatologic Clinics, 27(2), 133-136. vi. https://doi. org/10.1016/j.det.2008.11.010

19. Verbeek JH, Rajamaki B, Ijaz S, et al. Personal protective equipment for preventing highly infectious diseases due to exposure to contaminated body fluids in healthcare staff. Cochrane Database of Systematic Reviews. 2020;4: 34-48. https:// doi.org/10.1002/14651858.CD011621.pub4.

20. Houghton C, Meskell P, Delaney H et al. Barriers and facilitators to healthcare workers' adherence with infection prevention and control (IPC) guidelines for respiratory infectious diseases: a rapid qualitative evidence synthesis. Cochrane Database of Systematic Reviews. 2020;4:CD013582.https:// login.research4life.org/tacsgr1doi_ org/10.1002/14651858.CD01358.

21. Menon J, Shanmugam N, Patel K, Hakeem A, Reddy MS, Rela M. Awareness and concerns about novel coronavirus disease 2019 (COVID-19) among parents of pediatric liver transplant recipients. Pediatr Transplant. 2020;24(8):2-7.

Citation: Silwal S, Khadgi D, Mahato A, Basnet S, Thapa S, Niraula A. Lived Experiences of COVID-19 Survivors in Nepal: A Phenomenological Analysis. JCMS Nepal. 2021 ; 17(4); 298-307. 